\title{
O ENSINO DE BIOLOGIA CELULAR E A TEORIA DE APRENDIZAGEM DE DAVID AUSUBEL
}

Evelyse Lemos Borges*

A educação escolar brasileira vive hoje problemas e dificuldades de diferentes naturezas. No nível macroestrutural esses problemas decorrem, fundamentalmente, do descaso do Estado para com a escola pública, manifestandose, por exemplo, na ausência de uma política educacional efetivamente voltada para sua recuperação, de forma a garantir um ensino de boa qualidade às classes populares que constituem a maior parcela de sua clientela. Esse descompromisso se reflete negativamente no nível microestrutural -da escola e da sala de aula- de inúmeras formas, principalmente pelas salas de aula superlotadas e pela carência de equipamentos (que são reflexos da realidade econômico-social do país), pelos professores mal preparados, uma vez que os cursos de licenciatura não estão conseguindo despertá-los e formá-los para a função de professor enquanto profissional do ensino, não conseguindo que percebam como se forma a estrutura cognitiva dos in-

- Graduada em Ciências Biológicas pela UGF-RJ, pós-graduada (lato sensu) em Metodologia do Ensino Superior, professora de Biologia Celular no curso Licenciatura em Ciências Biológicas da SOCIGRAN. A autora é coordenadora do mesmo curso e aluna do programa de Mestrado em Educação na UCDB. 
divíduos, de modo a fazer com que o processo ensino-aprendizagem se realize de forma adequada, não proporcionando aos alunos uma aprendizagem fragmentada e mecânica.

Não se percebe, na prática diária do professor, a preocupação de se relacionar os conhecimentos do cotidiano com o que deve ser assimilado de uma disciplina, e nem os conteúdos de uma delas com os das demais. O ensino de Biologia, especificamente, tem acontecido de maneira fragmentada, sem nenhuma relação com o cotidiano dos alunos e, segundo Miriam Krasilchik (1983), limitando-se a apresentar a ciência completamente desvinculada de suas aplicações e das relações que tem com o dia-a-dia do estudante.

O presente trabalho pretende expor reflexões e sugestões resultantes de uma experiência do ensino de biologia no nível de $2^{\circ}$ grau, na tentativa de ajudar aqueles que estão preocupados com a melhoria do ensino dessa disciplina.

Será feita uma descrição dos problemas observados no ensino e aprendizado que levaram à reestruturação do conteúdo programático da disciplina com ḅase na Teoria de Aprendizagem de David Ausubel por meio do uso de mapas conceituais.

\section{O ENSINO DE BIOLOGIA}

Biologia - do grego BIÓS, "vida", e LOGIA, "tratado, ciência, discurso". Pela formação da palavra, vê-se que o seu significado é muito amplo, ou seja, biologia significa ciência ou estudo da vida. Com a infinidade de tipos 
diferentes de seres vivos, encontrados no ambiente, percebese com naturalidade sua fragmentação em campos distintos, embora, todas as áreas estejam interligadas, já que se ocupam da vida e dos seres vivos.

Por essa razão, o estudo da Biologia no ensino básico é dividido em suas principais áreas de interesse - o meio ambiente, os seres vivos e a interação entre eles. Com essa divisão, a partir da $1^{\mathrm{a}}$ série do $1^{\circ}$ grau, esses temas centrais são ensinados e repetidos na $2^{\mathrm{a}}$ etapa do $1^{\circ}$ grau $\left(5^{\mathrm{a}}\right.$ a $8^{\mathrm{a}}$ séries) e no $2^{\circ}$ grau. É certo que a cada reapresentação dos assuntos ocorre um maior detalhamento, o que deveria assegurar um ensino mais coerente e articulado e, conseqüentemente, com sucesso.

Nas séries iniciais, os temas seriam apresentados às crianças numa abordagem adequada à sua estrutura cognitiva, de modo a perceberem as diferenças entre os seres vivos e não vivos e, também, que nenhum ser vivo consegue sobreviver isolado, sem se relacionar com o ambiente e com outros seres vivos.

Com o desenvolvimento da criança e a repetição dos conteúdos nas etapas mais avançadas do ensino, esta deveria perceber que o homem não é o único ser vivo importante no mundo, e que o macro, facilmente observado por ela, não é tudo. Ao contrário, o mundo palpável e facilmente visualizado só existe e funciona graças à interação de várias funções que acontecem em nível microscópico.

Durante minha vida profissional, verifiquei que essa interligação entre as diversas áreas da Biologia é pouco percebida pela maioria dos alunos (de qualquer nível de escolaridade) e, em conseqüência, a consideram uma 
disciplina chata, decorativa, com conteúdos soltos e totalmente sem interesse para a vida cotidiana dos mesmos.

Considero que esses pensamentos são resultantes em grande parte de uma prática docente inadequada, e de uma formação incompleta, pois apesar de se esforçarem, os professores não estão conseguindo organizar o trabalho didático de modo que os alunos superem os conceitos espontâneos - parcialmente verdadeiros ou errôneos - que contribuem para a formação do senso comum - o que faz com que estes ingressem na universidade, apresentando deficiência quanto à aprendizagem de conceitos básicos.

Tal problema, do ensino da Biologia, é o mesmo característico de toda a educação escolarizada brasileira, e, comojáse disse, pode aqui também ser explicado por inúmeros fatores como: salas de aula superlotadas, ambientes e equipamentos inadequados, professores mal preparados, mal remunerados, livros didáticos que abordam os fenômenos biológicos como se fossem isolados e independentes, etc. Estes fatores fazem com que os alunos, pela "necessidade de nota", acabem "treinados" a alcançar uma aprendizagem mecânica, limitando-se a memorizar os conceitos prontos transmitidos pelos professores, e não se dando ao trabalho de traduzi-los para o seu próprio vocabulário e vida, criando, assim, uma falsa idéia de aprendizagem a partir da memorização de algumas palavras ou frases.

$\mathrm{Na}$ Psicologia da Educação, diferentes explicações de como se dá a aprendizagem serviram e servem de fundamentação para a organização do processo ensinoaprendizagem. Tradicionalmente, considerava-se o conhecimento transmitido pelos professores como verdadeiro, 
definitivo e inquestionável. O professor era dono desse saber e, por isso, a parte ativa do processo ensino-aprendizagem. Ativo porque os alunos, "tábulas rasas", recebiam passivamente os conhecimentos por ele transmitidos de fora para dentro como num processo de impressão.

Uma outra maneira de explicar como se processa a aprendizagem é a apriorista, que defende a idéia de que cada indivíduo tem um potencial inato, ou seja, ao nascer ele traz toda uma bagagem que deverá ser "despertada" e desenvolvida ao longo de sua vida. Com o desenvolvimento da Psicologia Educacional, ampliou-se os conhecimentos sobre a aprendizagem e ensino, e verificou-se que saber como os indivíduos aprendem possibilita aos professores adequar procedimentos e organizar o conteúdo de ensino, de modo a promover uma significativa melhoria na qualidade do ensino.

Atualmente, as explicações sobre a aprendizagem dada pela concepção cognitivista tem oferecido mais claros subsídios ao trabalho docente, que visa a aprendizagem significativa. Nela, professor e aluno devem interagir dinamicamente; o professor atuando como mediador entre o conteúdo a ser aprendido e o sujeito que aprende, poderá perceber as dificuldades do aluno e, com adequação, organizar o ensino de forma a favorecer um processo de aprendizagem reflexivo, onde o estudante será o construtor do seu próprio saber.

Penso que uma possível solução para a melhoria do ensino de Biologia é conscientizar os acadêmicos sobre o que é ser professor e ser aluno e sobre como se processa a aprendizagem do indivíduo e prepará-los com 
metodologia simples, eficiente, que tenha relação com a realidade local.

Para isso, considero importante que os mesmos tenham, ao longo do curso, aulas cuidadosamente planejadas, visando favorecer a aprendizagem significativa e servir como referência e exemplo para a prática profissional. Entendo também que a metodologia de ensino não deve ser preocupação exclusiva do professor, uma vez que

"Não adianta ensinar aos licenciados coisas que não se relacionam com o que eles vão ter que ensinar no secundário, e não adianta ensinar-lhes por métodos inadequados, pois eles ensinarão como foram ensinados (o grifo é nosso). Quando nos convenceremos disso?" (Oswaldo Frota-Pessoa, 1991:60)

\section{A DISCIPLINA BIOLOGIA CELULAR E A TEORIA DE APRENDIZAGEM DE DAVID AUSUBEL}

Esta disciplina tem como objetivo principal relacionar o metabolismo dos seres vivos, unicelulares ou pluricelulares, com o metabolismo celular, ou seja, é fundamental que, no decorrer do ano letivo, o aluno perceba que o funcionamento do organismo como um todo é diretamente dependente do trabalho de cada célula que o forma. Por ser essencial para o bom entendimento de outras disciplinas mais específicas, é fundamental que,no final do ano letivo, os alunos consigam perceber as interligações entre célula e organismos mais complexos. 
Analisando o conteúdo programático da mesma, percebo que ele é adequado para o que se propõe, porém ainda observo, no final de cada ano letivo, um grande grupo de alunos que não consegue alcançar o objetivo da mesma. Acredito que uma dificuldade seja a maneira pela qual o mesmo é organizado, do conceito mais específico para o mais geral, dificultando uma visualização geral da disciplina e relacionamento desta com conhecimetos prévios dos alunos.

É nesse sentido que se faz necessário conhecer e aplicar a Teoria de Aprendizagem de David Ausubel que, ao explicar como se forma a estrutura cognitiva de um indivíduo, deixa claro como o professor deve planejar o conteúdo de ensino para a aprendizagem do aluno. Partindo do pressuposto de que uma das possíveis soluções para o problema educacional é formar profissionais competentes e que a referida teoria é importantíssima para a capacitação dos mesmos, reorganizei o conteúdo programático da disciplina Biologia Celular.

A teoria explica que a estrutura cognitiva do aluno é o principal fator que influencia a aprendizagem significativa (Ronca, 1978:59) e, por isso, defende a importância de se ensinar o aluno a partir dos conhecimentos que ele já possui. Ausubel define a estrutura cognitiva do indivíduo como o conjunto de idéias, conceitos, proposições construído de maneira hierarquizada, onde os conceitos mais gerais estão num topo e englobam outros, menos abrangentes.

“...Ausubel vê o armazenamento de informações no cérebro humano como sendo altamente organizado, formando uma hierarquia conceitual na qual elementos mais especificos 
de conhecimento são ligados (e assimilados) a conceitos mais gerais, mais inclusivos. Estrutura cognitiva significa, portanto, uma estrutura hierárquica de conceitos na mente do individuo." (Moreira, M.A.e Buchweitz, B. Mapas Conceituais, 1987:17)

A aprendizagem significativa, segundo o mesmo autor, ocorre quando o indivíduo consegue relacionar o conteúdo a ser aprendido com aquilo que ele já sabe, conseguindo assim generalizar e expressar o conteúdo com sua própria linguagem. Ao conseguir essa generalização, dizse que houve aprendizagem significativa com substantividade.

Referindo-se ao processo ensino-aprendizgem, Ausubel compara o conteúdo das disciplinas de qualquer nível de escolaridade com a estrutura cognitiva do aluno (uma é lógica, a outra psicológica, respectivamente) e mostra que ambos são organizados de maneira hierárquica, onde no topo do conjunto estão um número de conceitos verdadeiramente amplos que incluem os menos abrangentes. Ao fazer essa relação, fica claro que a organização do conhecimento é a principal variável para a aprendizagem do aluno e a grande tarefa do professor na seleção e arranjo do que vai ser ensinado. Torna-se necessário, portanto, que o professor identifique em cada disciplina os conceitos mais importantes e mais abrangentes e que planeje cada atividade com atenção aos conhecimentos anteriores dos alunos, para que os mesmos aprendam os conceitos básicos da disciplina, significativamente, e formem na sua própria estrutura cognitiva um sistema de processamento de informações. Assim, os conhecimentos espontâneos, de senso comum, 
devem evoluir para os científicos.

$\mathrm{O}$ aluno, para aprender significativamente, precisa relacionar o conteúdo novo com aquilo que ele já sabe e, também, manifestar uma predisposição positiva para aprender. Esse relacionamento deve ser substantivo e não arbitrário, ou seja, a relação entre os conceitos novos e os já existentes na sua estrutura cognitiva não deve ser alterada, mesmo que símbolos diferentes, mas equivalentes, sejam usados.

Em nossas escolas essa aprendizagem é dificultada porque os professores não costumam ter bem definidos os conceitos relevantes de suas próprias disciplinas e a rede conceitural formada por eles e, por isso, não aceitam respostas diferentes das que ensinaram, induzindo os alunos a aprenderem mecanicamente, decorando conceitos arbitrariamente, sem compreender seus significados, suas relações, porque eles próprios as ignoram ou não as valorizam. Outro fator de dificuldade é que, na maioria das vezes, os novos temas são apresentados de maneira aleatória, sem ser feita qualquer associação com conhecimentos préexistentes na estrutura cognitiva do aluno.

Os seguidores da teoria ausubeliana utilizam e aconselham o uso de mapas conceituais como um instrumento metodológico, que apesar de nunca ter sido indicado por ele, é um tipo de organização de conceitos de forma hierárquica, do mais abrangente para o menos abrangente, num plano bidimensional, facilitando ao estudante visualizar as interrelações entre os diversos conceitos estudados. É, portanto, um recurso instrucional, na medida em que favorece a aprendizagem de conceitos, 
já que permitem o "descer e subir nas estruturas conceituais hierárquicas à medida que a nova informação é apresentada". (Novak 1977, 1981)

Em Biologia Celular, numa reorganização da disciplina, foram selecionados da máteria conceitos-chaves e elaborado, com eles, um mapa conceitual; para o desenvolvimento do trabalho com os alunos foi elaborado um questionário sobre este conteúdo aplicado como préteste no primeiro dia letivo.

No mapa conceitual, como conceito geral, que ficará no topo do mapa é usado como subsunçor (idéia mais ampla, que funciona como subordinador de outros conceitos na estrutura cognitiva e como ancoradouro no processo de assimilação), foi selecionado seres vivos porque, além de ser o objeto de estudo da Biologia, é um termo facilmente exemplificado por alunos de diferentes níveis de escolaridade. Partindo deste conceito, o conteúdo programático da disciplina foi reestruturado, de maneira que a sua organização obedeceu uma seqüência crescente de complexidade, passou a ser bidimensional, evidenciando esta seqüência, e também suas interrelações.

Pela experiência de magistério que tenho, percebo que os alunos, mesmo ingressando na faculdade, têm visão antropocêntrica de vida, sabem exemplificar os seres vivos mas, dificilmente, conseguem explicar o termo cientificamente. Portanto, no segundo encontro, em classe, este deverá ser o objeto de discussão.

Por meio dessa discussão, certamente, chegaremos a um mapa conceitual como, ou muito próximo, do que está representado abaixo. Nele percebe-se que o conceito geral 


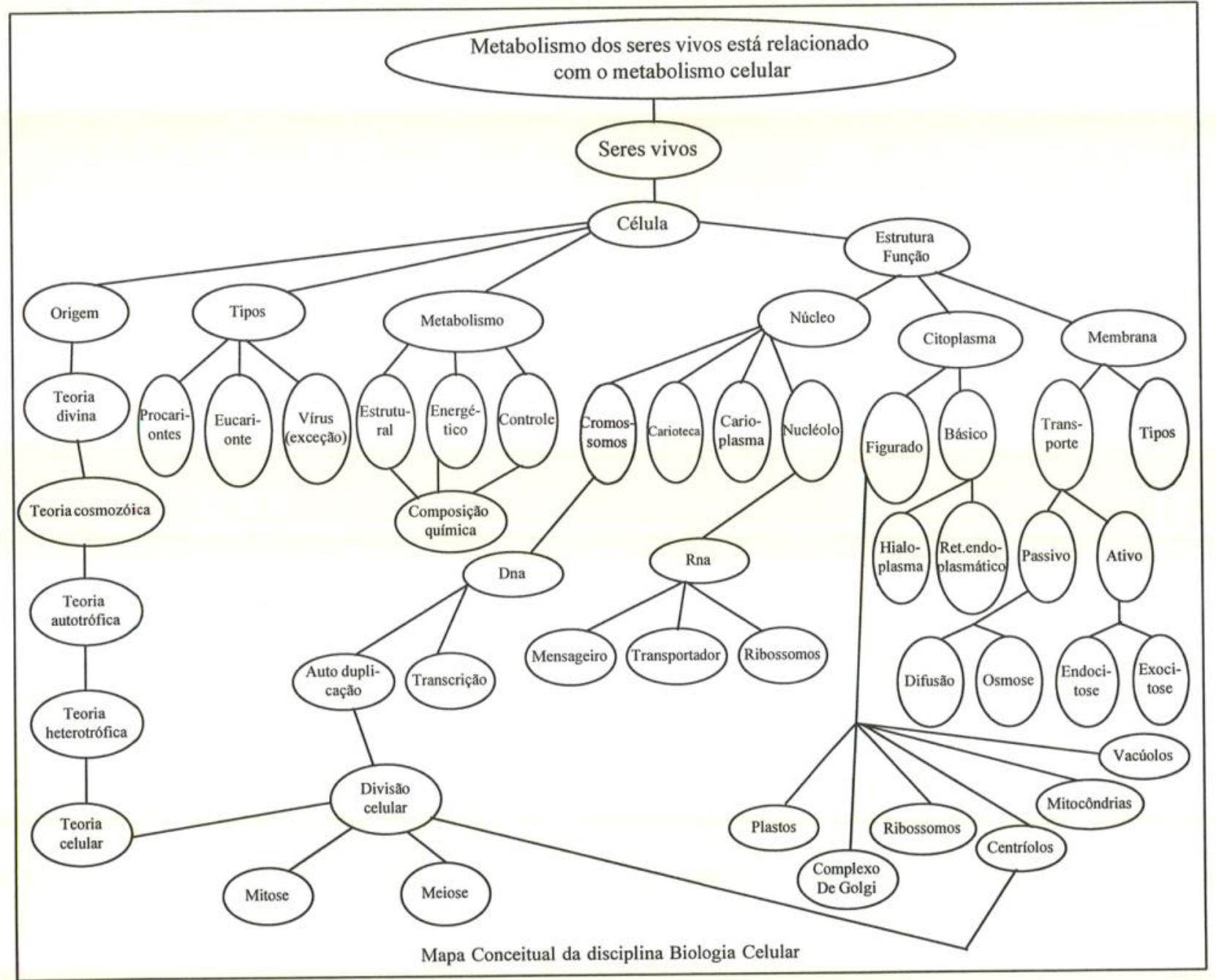


-seres vivos- abrange vários outros menos gerais e, estes, por sua vez, diferenciam-se em outros mais específicos. Já neste primeiro contato com tal instrumento será possível fazer com que os alunos percebam as interrelações entre os conceitos, na sua maioria por eles já conhecidos, e também as relações de inclusibilidade subordinada e superordenada.

Dessa caracterização serão selecionados os conceitos mais relevantes do programa de citologia, que são: origem da vida; tipos celulares; metabolismo celular e estrutura e função da célula. Nessa primeira divisão os alunos devem perceber porque os seres vivos são diferentes dos

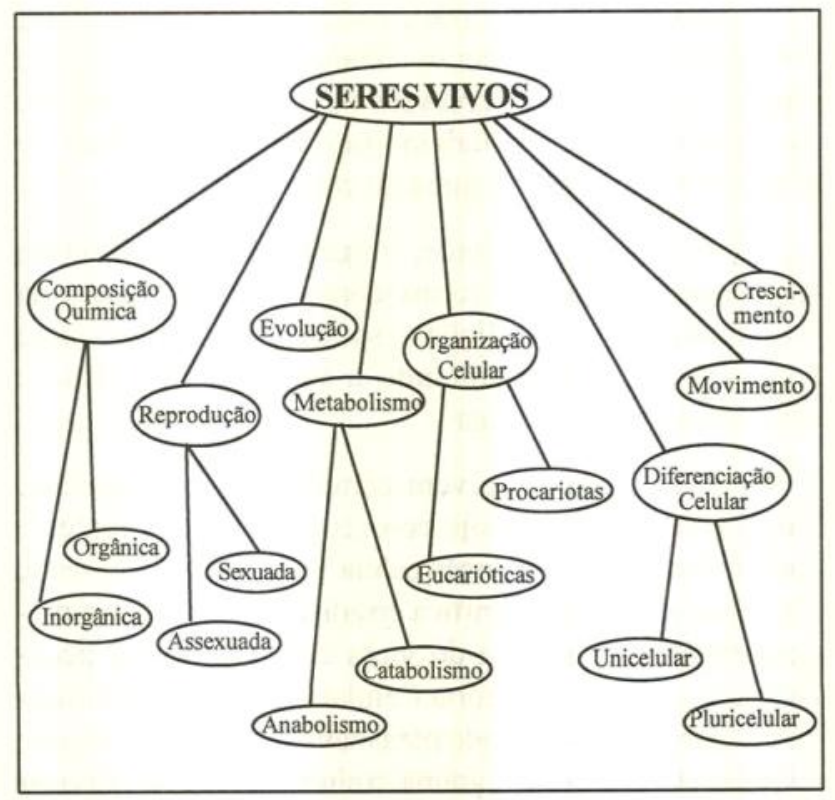


seres não vivos, que todos tiveram uma origem, que são formados por células, que têm metabolismo, que esse metabolismo existe graças ao trabalho de várias partes menores que integram as células. Assim, o mapa cresce longitudinalmente e transversalmente, evidenciando as diversas relações entre os conceitos.

O mapa completo, apesar de já elaborado, não é definitivo e único. Ao longo do período letivo e de acordo com o grupo que o está utilizando, poderá sofrer modificações. Cada novo assunto poderá ser introduzido por um organizador prévio, tópicos já discutidos e aprendidos anteriormente.

A partir dessa visão, cada unidade poderá ser trabalhada individualmente, sendo que o mapa com o programa globalizado deverá ser utilizado sempre para que os alunos possam visualizar rapidamente o nível de abrangência do conceito que estiver sendo estudado.

A primeira unidade, origem da vida, objetiva apresentar ao aluno as diversas teorias da formação da vida no planeta e que condições especiais permitiram esse acontecimento, relacionando a vida com a célula e enunciando a teoria celular.

A segunda parte vem complementar a primeira, mostrando que ainda hoje co-existem células simples e complexas, isto é, a evolução celular (e, conseqüentemente, dos seres vivos) não significa erradicação das células préexistentes. A existência do vírus com todas suas peculiaridades não nega a Teoria Celular, já que eles só conseguem reproduzir-se quando parasitam algum tipo de célula. Ainda nesta etapa do programa, o aluno deverá caracterizar 
diferenças e semelhanças entre células procariotas, eucariotas e vírus, além de reconhecer os diferentes tipos de células eucariotas.

$\mathrm{Na}$ terceira etapa, os alunos devem perceber que apesar de formadas por moléculas comuns ao meio ambiente, estas se organizam nas células de forma característica, formando várias organelas distintas que exercem funções diferentes dentro de uma única célula. Assim teremos um conjunto de reações químicas responsáveis pela liberação ou armazenamento de energia, outras, responsáveis pela determinação da própria estrutura celular e outras que controlam todas as funções menores, mostrando que elas precisam interagir de forma adequada.

A quarta etapa serve para sistematizar todo o conteúdo trabalhado até então, ou seja, o aluno discutiu o trabalho celular como um todo e agora ele deverá conhecer detalhadamente a estrutura das organelas celulares e suas funções, relacionando-as com os diferentes tipos de metabolismo celular.

Destaca-se que o conteúdo não é novo para nenhum dos alunos; o que se pretende é evitar que mais uma vez eles façam uma aprendizagem mecânica por ainda não terem conseguido relacionar os conceitos entre si. Os exemplos -organizadores prévios- serão utilizados para possibilitar o relacionamento com os conceitos já disponiveis na estrutura cognitiva de cada aluno, com os que foram aprendidos mecanicamente em outros momentos, ou seja, é preciso que os alunos atribuam significados relacionados com sua estrutura cognitiva. 
Para favorecer a aprendizagem significativa dos alunos, Ausubel sugere técnicas simples que satisfazem o cotidiano da maioria das aulas e, com esses princípios, defende a aula expositiva como uma boa técnica didática, desde que não seja única.

O aluno deve estar consciente de que sem esforço não conseguirá uma aprendizagem significativa; o professor, por sua vez, deverá facilitar esta aprendizagem, criando meios para que o aluno faça as relações entre os conceitos aprendidos anteriormente de forma mecânica.

Comparando este meu programa com o anterior, fica claro que as interrelações dos diferentes conceitos poderão ser mais facilmente percebidas com o auxílio dos mapas conceituais e organizadores prévios, já que estes possibilitam a visualização de uma organização conceitual semelhante a que se processa na sua própria estrutura cognitiva.

Finalmente, vale ressaltar que a referida prática é uma alternativa de melhoria da qualidade do ensino, dentro da realidade brasileira, sem o uso de recursos caros. Fazer um levantamento da realidade dos alunos para descobrir o que eles já sabem e construir mapas conceituais a partir daí, relacionando esse conhecimento prévio com os conceitos a serem aprendidos, depende exclusivamente da disposição dos professores. Portanto, é bastante provável que este instrumento possa ser utilizado com sucesso na superação das dificuldades do ensino de Biologia, em todos os níveis escolares, e especialmente útil na formação de professores. 


\section{REFERÊNCIAS BIBLIOGRAFIAS}

ELAM, Stanley. (compilação). A educação e a estrutura do conhecimento. Buenos Aires : El Ateneo, 1973.

FROTA-PESSOA, O. Como tratar conteúdos tradicionais na licenciatura moderna. Anais $4^{\circ}$ Encontro "Perspectivas do ensino de Biologia". São Paulo : FE - USP, 1991.

GIL, Antônio Carlos. Como elaborar projetos de pesquisa. São Paulo : Atlas, 1991.

JUNQUEIRA, L.C., CARNEIRO, J. Biologia celular e molecular. Rio de Janeiro : Guanabara Koogan, 1991.

KRASILCHIK, M. Prática de ensino de Biologia. São Paulo : Harbra, 1983.

MOREIRA, Marco Antonio. Atividade docente na universidade: alternativas instrucionais. Rio Grande do Sul : D. C. Luzzato, 1985.

MOREIRA, M.A., BUCHVVEITZ, B. Mapas conceituais: instrumentos didáticos, de avaliação e de análise de currículo. São Paulo : Ed. Moraes, 1987. 